\title{
The emerging roles of ADAMTS-7 and ADAMTS- 12 matrix metalloproteinases
}

This article was published in the following Dove Press journal:

Open Access Rheumatology Research and Reviews

22 September 2009

Number of times this article has been viewed

\author{
Edward A Lin' \\ Chuan-ju Liu' ${ }^{1,2}$ \\ 'Department of Orthopaedic Surgery, \\ ${ }^{2}$ Department of Cell Biology, New \\ York University School of Medicine, \\ New York, NY, USA
}

\begin{abstract}
The a disintegrin and metalloproteinase with thrombospondin motifs (ADAMTS) comprise a family of secreted zinc metalloproteinases with a precisely ordered modular organization. These enzymes play an important role in the turnover of extracellular matrix proteins in various tissues and their dysregulation has been implicated in disease-related processes such as arthritis, atherosclerosis, cancer, and inflammation. ADAMTS-7 and ADAMTS-12 share a similar domain organization to each other and form a subgroup within the ADAMTS family. Emerging evidence suggests that ADAMTS-7 and ADAMTS-12 may play an important role in the development and pathogenesis of various kinds of diseases. In this review, we summarize what is currently known about the roles of these two metalloproteinases, with a special focus on their involvement in chondrogenesis, endochondral ossification, and the pathogenesis of arthritis, atherosclerosis, and cancer. The future study of ADAMTS-7 and ADAMTS-12, as well as the molecules with which they interact, will help us to better understand a variety of human diseases from both a biological and therapeutic standpoint.
\end{abstract}

Keywords: ADAMTS-7, ADAMTS-12, COMP, GEP, arthritis, chondrogenesis, atherosclerosis

\section{Introduction}

The a disintegrin and metalloproteinase with thrombospondin motifs (ADAMTS) are zinc matrix metalloproteinases (MMPs) with a precisely ordered modular organization. ADAMTS comprises a family of secreted proteinases, many of which bind to and modulate extracellular matrix proteins. The ADAMTSs are translated initially as inactive pre-proenzymes, whose structure includes a signal peptide, pro-domain, catalytic domain, disintegrin-like domain, a central thrombospondin type I-like (TSP) repeat, a cysteine-rich domain, a spacer region, and a variable number of C-terminal TSP repeats. ADAMTSs can occur in multiple isoforms due to alternative splicing. ${ }^{1,2}$

First identified in 1997, members of the ADAMTS family are involved in diseases ranging from coagulation disorders to malignancy (Table 1). ${ }^{3-6}$ ADAMTS-13 plays a role in the development of the coagulation disorder, thrombotic thrombocytopenic purpura. ${ }^{5,7-9}$ Patients with Ehler-Danlos syndrome type $7 \mathrm{C}$, a genetic disorder of collagen synthesis, have mutations in the ADAMTS-2 gene. ${ }^{10,11}$ These mutations have also been associated with bovine dermatopraxis, an inherited disorder characterized by severe skin fragility. ${ }^{10}$ ADAMTS- 1 exhibits angioinhibitory properties and is crucial for the development and function of the urogenital system. ${ }^{12-14}$ ADAMTS-1 may also contribute to atherosclerosis by cleaving versican, a component of extracellular matrix (ECM).${ }^{15}$ Indeed, mutations in ADAMTS- 1 have been associated with an increased risk of coronary artery disease. ${ }^{16}$ Other ADAMTS, including ADAMTS-4 and 8 , have also

submit your manuscript $\mid$ www.dovepress.con 
Table I Biological roles of ADAMTS metalloproteinases

\begin{tabular}{|c|c|c|c|}
\hline ADAMTS & Alternative name(s) & Known substrate(s) & Biological role \\
\hline $\mathrm{I}$ & METH-I & Aggrecan, versican & $\begin{array}{l}\text { Antiangiogenesis }{ }^{106} \\
\text { Renal interstitial fibrosis } 14,107 \\
\text { Bone remodeling } \\
\text { Ovarian folliculogenesis } \\
\text { Atherosclerosis }^{15} \\
\text { Urogenital development } \\
\text { Tumor growth/remodeling }\end{array}$ \\
\hline 2 & PCINP & Collagen I, II and III N-propeptides & $\begin{array}{l}\text { Ehler-Danlos syndrome type } 7 C^{10,11} \\
\text { Bovine dermatopraxis }{ }^{10}\end{array}$ \\
\hline 3 & KIAA0366 & Procollagen II N-propeptide & \\
\hline 4 & Aggrecanase-I & $\begin{array}{l}\text { Aggrecan, brevican, COMP, } \\
\text { decorin, fibromodulin, versican }\end{array}$ & $\begin{array}{l}\text { Arthritis }^{114-117} \\
\text { Atherosclerosis }^{17,18} \\
\text { Tendinopathy }\end{array}$ \\
\hline 5 & Aggrecanase-2ADAMTS-II & Aggrecan, brevican & $\begin{array}{l}\text { Arthritis }{ }^{19-22} \\
\text { Glioblastoma }^{97}\end{array}$ \\
\hline 6 & NA & NA & \\
\hline 7 & ADAMTS-7B & COMP, $\alpha 2 M$ & Arthritis \\
\hline 8 & METH-2 & Aggrecan & $\begin{array}{l}\text { Antiangiogenesis } \\
\text { Brain malignancy } \\
\text { Arthritis }^{23} \\
\text { Atherosclerosis } \\
17,18\end{array}$ \\
\hline 9 & $\mathrm{KIAAI} 3 \mathrm{I} 2$ & Aggrecan, versican & Arthritis $^{121}$ \\
\hline 10 & NA & NA & \\
\hline 12 & NA & Aggrecan, COMP, $\alpha 2 M$ & Arthritis \\
\hline 13 & VWFCP & von Willebrand factor & Thrombotic thrombocytopenic purpura ${ }^{5,7-9}$ \\
\hline 14 & NA & Procollagen I, II N-propeptide & \\
\hline 15 & NA & Aggrecan & \\
\hline 16 & NA & $\alpha 2 M$ & \\
\hline 17 & NA & NA & \\
\hline 18 & NA & NA & Antithrombosis/stroke ${ }^{122}$ \\
\hline 19 & NA & Aggrecan & \\
\hline 20 & NA & Aggrecan & \\
\hline
\end{tabular}

Abbreviations: ADAMTS, a disintegrin and metalloproteinase with thrombospondin motifs; METH, metalloprotease and thrombospondin- I; PCINP, pro-collagen I N-proteinase; COMP, cartilage oligomeric matrix protein; a2M, alpha 2-macroglobulin; vWFCP, von Willebrand factor-cleaving protease.

been implicated in the formation of atherosclerotic plaque and atherothrombotic disease. ${ }^{17,18}$ ADAMTS-5 has also been associated with osteoarthritis and other inflammatory joint diseases due to its ability to degrade aggrecan. ${ }^{19-22}$ In addition, other ADAMTS, including ADAMTS-1, 4, 8, $9,12,16$, and 18 have also been shown to cleave aggrecan in vitro. ${ }^{20,23-27}$

Two recently discovered members of the ADAMTS family, ADAMTS-7 and ADAMTS-12, form a subgroup within the ADAMTS family based on their shared domain organization (Figure 1). Emerging evidence suggests that ADAMTS-7 and ADAMTS-12 may play a key role in the pathogenesis of important diseases, such as arthritis, atherosclerosis, and cancer. ${ }^{3,28,29}$ In this review, we summarize what is currently known about the roles of ADAMTS-7 and ADAMTS-12 in the pathogenesis of these diseases as well as in other important biological processes.

\section{Role in arthritis}

The notion that MMPs and ADAMTSs play an important role in osteoarthritis and rheumatoid arthritis has been well established. ${ }^{29-36}$ In one study, ADAMTS-7 was found to be significantly upregulated in arthritic cartilage and synovium compared with normal controls. ${ }^{37}$ Quantitative real-time polymerase chain reaction (PCR) has revealed that while ADAMTS-7 and -12 are both significantly upregulated in RA cartilage, only ADAMTS-12 is significantly upregulated in OA cartilage (unpublished data). ${ }^{37,38}$ 


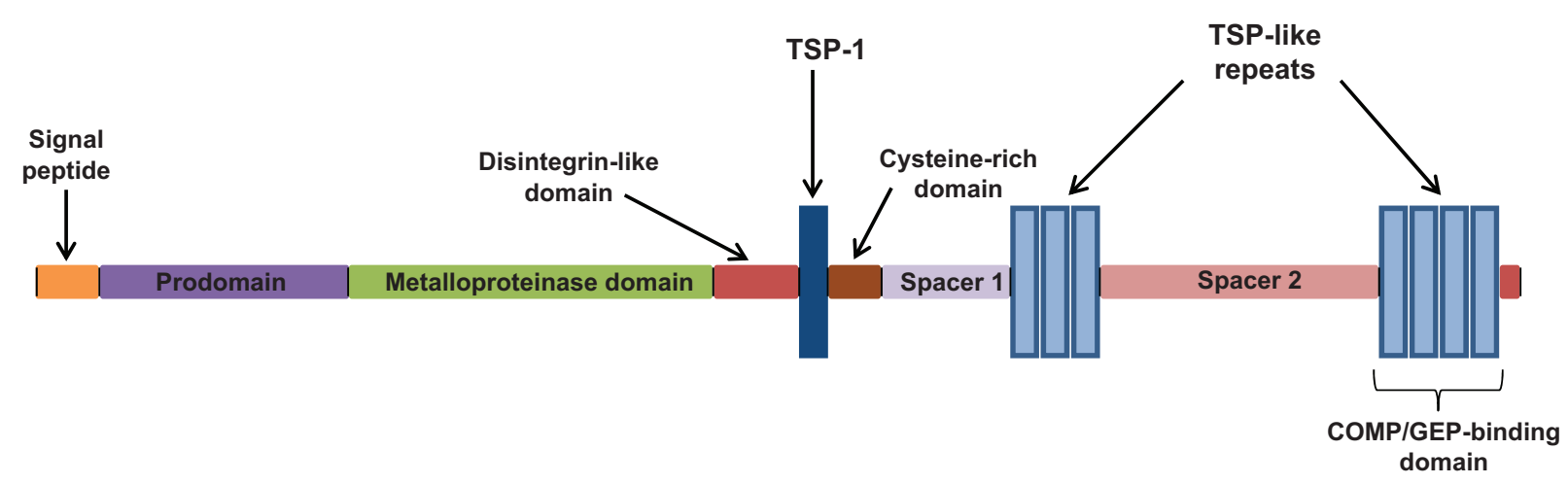

Figure I Schematic representation of the domain organization of ADAMTS-7/-12. The C-terminal COMP/GEP-binding TSPI motifs are indicated.

Abbreviations: ADAMTS, a disintegrin and metalloproteinase with thrombospondin motifs; COMP, cartilage oligomeric matrix protein; GEP, granulin-epithelin precursor.

The inflammatory cytokines, tumor necrosis factor (TNF) and interleukin (IL)-1 $\beta$ have been previously shown to induce the expression of a number of MMPs involved in the development and progression of arthritis. ${ }^{39-43}$ Real-time PCR analysis of cultured human cartilage explants show that both TNF and IL-1 $\beta$ strongly induce ADAMTS-7 and ADAMTS-12 expression. ${ }^{44}$ Interestingly, this induction does not occur for ADAMTS-12 in human fetal fibroblasts, suggesting that there may be some tissue specificity for this effect. ${ }^{45}$

\section{Interaction with COMP}

Arthritis is a disease process characterized by the proteolytic degradation of ECM components with subsequent loss of articular cartilage and bone. Cartilage oligomeric matrix protein (COMP), a $524 \mathrm{kDa}$ disulfide-bonded multidomain glycoprotein composed of five $110 \mathrm{kDa}$ subunits, is a prominent noncollagenous component of cartilage ECM. ${ }^{46}$ Mutations in the human COMP gene have been linked to the development of pseudoachondroplasia and multiple epiphyseal dysplasia, which are autosomal-dominant forms of short-limb dwarfism. ${ }^{47-50}$ Although the function of COMP is not completely understood, it appears to mediate chondrocyte attachment via an integrin receptor. ${ }^{51,52}$ Accumulating evidence suggests that COMP may function to stabilize the ECM of articular cartilage by specific interactions with matrix components including collagen type II and IX, aggrecan, and fibronectin. ${ }^{53-56}$ Fragments of COMP have been detected in the diseased cartilage, synovial fluid, and serum of patients with post-traumatic knee injuries, primary osteoarthritis (OA) and rheumatoid arthritis (RA). ${ }^{57,58}$ This suggests that COMP degradation may play a key role in these disease processes. Furthermore, several recent studies have suggested that monitoring COMP levels in joint fluid and/or serum may be useful in assessing the progression of arthritis in a clinical setting. ${ }^{59-64}$ Thus, the study of COMP-degradative enzymes is of potential significance; both to elucidate the mechanism of disease as well as for the development of novel approaches to the diagnosis and therapy of arthritis.

Purified COMP is digested by several MMPs in vitro, including MMP-1, MMP-3, MMP-9, MMP-13, MMP-19, and MMP-20 ${ }^{65,66}$ A member of the ADAMTS family, ADAMTS-4, has also been reported to cleave COMP in vitro.$^{67}$ Despite these findings, the exact role of MMPs in COMP degradation has yet to be confirmed by in vivo animal studies.

The relationship between ADAMTS-7, ADAMTS-12, and COMP was first established in our lab via a functional genetic study involving the yeast-hybrid system, which identified both ADAMTS- 7 and -12 as binding partners of COMP. ${ }^{37,68}$ This result has also been confirmed by coimmunoprecipitation studies suggesting that ADAMTS-7 and -12 bind specifically to COMP in vivo. Furthermore, an analysis of ADAMTS-7 and - 12 deletion mutants has revealed that four $\mathrm{C}$-terminal thrombospondin type-1 repeats are conserved in both enzymes and are required for binding to the EGF-like domain of COMP and subsequent COMP cleavage. ${ }^{37,68}$ These findings are in accordance with the notion that $\mathrm{C}$-terminal domains of metalloproteinases are important for determining substrate specificity. ${ }^{69}$

ADAMTS-7 is expressed in bone, cartilage, synovium, tendon, and ligament, all of which contain COMP. ${ }^{46,51}$ Although northern blot analysis has found ADAMTS-12 expression only in the fetal lung, real-time PCR analysis has detected ADAMTS-12 in cartilage, synovium, tendon, skeletal muscle, and fat. ${ }^{45,68}$ ADAMTS-7 is also detectable in meniscus, skeletal muscle, and fat. ${ }^{37}$ Through immunostaining analysis, we know that ADAMTS-7 and -12 co-localize 
with COMP both in the cytoplasm and on the surface of human chondrocytes. ${ }^{37,68}$ These studies also suggest that the interaction between ADAMTS-7 and -12 with the chondrocyte membrane may be mediated by COMP. Immunohistochemistry assays performed on embryonic murine limbs show significant overlap between COMP, ADAMTS-7, and ADMATS-12 expression patterns in vivo. ${ }^{37,68}$

Subsequent studies involving recombinant enzyme, conditioned medium, and purified protein have demonstrated that ADAMTS-7 and -12 can both digest COMP in vitro. An analysis of COMP fragments taken from in vitro assays suggests that ADAMTS-7 may cleave COMP at multiple sites. ${ }^{57}$ Interestingly, COMP fragments taken from the cartilage explants of osteoarthritis patients are of similar size to those found with in vitro studies $(110 \mathrm{kDa}) .{ }^{44}$ This highlights the possible role that the digestion of COMP by ADAMTS-7 and -12 may play in degenerative joint disease.

Since inflammatory cytokines TNF- $\alpha$ and IL- $1 \beta$ have been shown to induce the expression of ADAMTS-7 and -12 , these cytokines would also be expected to induce COMP degradation by upregulating these enzymes. Indeed, cells treated with both cytokines give rise to abundant levels of $110 \mathrm{kDa}$ COMP fragments. ${ }^{44}$ Furthermore, these fragments are completely eliminated in the presence of anti-ADAMTS-7 and ADAMTS-12 antibodies, providing strong evidence to suggest that ADAMTS-7 and -12 serve as key links between inflammatory cytokines and disease progression. ${ }^{37}$ These results have been further confirmed via small interfering RNA silencing of ADAMTS-7 and -12 in human chondrocytes. ${ }^{44}$ The next logical step would be to validate these findings in vivo by generating ADAMTS-7 or -12-null mice in an arthritis model. Previous findings involving ADAMTS-5 and aggrecan degradation in osteoarthritis and inflammatory arthritis mouse models have demonstrated the efficacy of this approach. ${ }^{24,26}$

\section{Interaction with GEP}

A recent study has found that COMP associates with a growth factor named granulin-epithelin precursor (GEP), which is strongly upregulated in the synovium of both OA and RA patients. ${ }^{70}$ GEP is also highly expressed in chondrocytes. ${ }^{70}$ First purified in the early 1990s, GEP is an $80 \mathrm{kDa}$ secreted glycoprotein, which contains seven and a half repeats of a cysteine-rich motif. ${ }^{71-74}$ Acting as an autocrine growth factor, GEP undergoes proteolytic processing with the liberation of $\sim 6 \mathrm{kDa}$ repeating units known as granulins, which retain at least some of the biologic activity of GEP. ${ }^{75}$
These peptides are active in cell growth assays and may be mediators of inflammation. ${ }^{76,77}$ GEP is also known by the names PC-cell derived growth factor, progranulin, proepithelin, and acrogranin.

The finding that COMP associates with both ADAMTS $-7^{37}$ and GEP $^{70}$ prompted us to determine whether GEP binds to ADAMTS-7 and whether ADAMTS-7, COMP, and GEP form a protein-protein interaction network. Data from our yeast-2-hybrid and coimmunoprecipitation assays show that ADAMTS-7 does indeed bind to GEP. ${ }^{78}$ Further experiments have found that the four $\mathrm{C}$-terminal TSP repeats of ADAMTS-7 are required for this interaction.

GEP has been shown to exhibit a potent antiprotease activity; it is an inhibitor of TNF-induced protease and GEP-derived granulin inhibits the protease thrombin. ${ }^{79,80}$ Unpublished data from our lab demonstrate that GEP specifically inhibits the ability of ADAMTS-7 and -12 to degrade COMP. Co-expression of GEP and ADAMTS-7 in a COMP-stable cell line results in a dose-dependent blockade of ADAMTS-7-mediated COMP degradation (Guo et al, unpublished data). Additionally, data from an in vitro digestion assay show that GEP prevents ADAMTS-12 from degrading COMP (Guo et al, unpublished data). Further data show that ADAMTS-7 can also be categorized as a GEP convertase, since it is involved in the proteolytic processing of GEP with the liberation of small fragments. ${ }^{78}$

The available data suggest that GEP inhibits the action of ADAMTS-7 via two distinct mechanisms. First, GEP inhibits the induction of ADAMTS-7 by inflammatory cytokines such as TNF- $\alpha$. Second, it disrupts the association between ADAMTS-7 and COMP via a direct protein-to-protein interaction. ${ }^{29}$ Thus, ADAMTS-7 and -12 metalloproteinases, COMP extracellular matrix protein, GEP growth factor, and TNF inflammatory cytokine all act in concert to form an key interaction and interplay network in the pathogenesis of arthritis (Figure 2).

\section{Role in chondrogenesis}

Chondrogenesis is a well orchestrated process mediated by interactions between cellular receptors, growth factors, and surrounding matrix proteins. These extracellular enzymes, which include the MMPs, lead to the activation of cell signaling pathways and gene expression in a temporalspatial-specific manner. Both ADAMTS-7 and -12 are expressed in musculoskeletal tissues, including cartilage, and are thus poised to play key roles in chondrogenesis. ${ }^{46,68,81}$ ADAMTS-7 and ADAMTS-12 are also highly expressed in the proliferative and pre-hypertrophic zones of growth. ${ }^{78,82}$ 


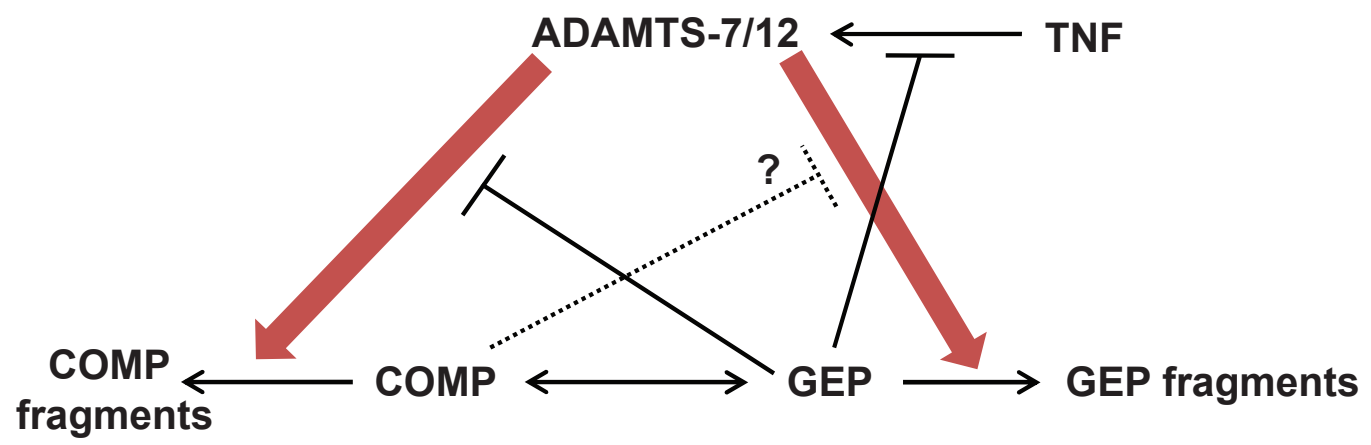

Figure 2 An interaction network among ADAMTS-7/-I2, COMP, and GEP. Arrows indicate a stimulatory effect. Crossed lines indicate an inhibitory effect. A dotted line indicates that the relationship is based on unpublished data.

Abbreviations: ADAMTS, a disintegrin and metalloproteinase with thrombospondin motifs; COMP, cartilage oligomeric matrix protein; GEP, granulin-epithelin precursor; TNF, tumor necrosis factor.

Initial real-time PCR data involving micromass cultures of a mouse embryonic mesenchymal stem cell line show that ADAMTS-7 is highly induced during the terminal stage of chondrogenic differentiation, which is accompanied by the increase of collagen-X expression. ${ }^{78}$ However, immunohistochemistry performed on mouse embryos show that ADAMTS-7 is abundantly expressed in both the early and late stages of cartilage development, as well as in chondrocytes throughout the mature growth plate. ${ }^{78}$ This suggests that ADAMTS-7 may play a significant role in chondrogenesis, and may influence various stages of cartilage development. ADAMTS- 12 is prominently expressed in proliferating and prehypertrophic chondrocytes in the embryonic growth plate. ${ }^{82}$

Given the expression pattern of ADAMTS-7 and -12 during various stages of chondrogenesis, their role in the process of chondrogenic differentiation has also been elucidated. Overexpression of either ADAMTS-7 or 12 in murine mesenchymal stem cells results in the potent inhibition of chondrocyte differentiation, specifically during the stage of chondrocyte hypertrophy. ${ }^{78,82}$ This effect can also be observed in fetal mouse metatarsal explants, where chondrocyte hypertrophy, mineralization, and bone length are significantly inhibited by ADAMTS-7-rich conditioned medium. Experiments with ADAMTS-12 in human mesenchymal stem cells have also led to similar results. ${ }^{82}$ Further experimentation has established that the chondrogenic inhibitory effect of ADAMTS- 7 and -12 depends specifically on four $\mathrm{C}$-terminal thrombospondin motifs. ${ }^{78,82}$

Once the inhibitory effect of ADAMTS-7 and -12 on chondrogenesis had been established, the focus was then shifted to finding the relevant upstream regulatory molecules of the signaling pathway. Both PTHrP and IHH are known regulators of chondrocyte differentiation.
They function through a negative feedback loop: PTHrP prevents chondrocyte hypertrophy, thus reducing levels of IHH which in turn, stimulates PTHrP expression. ${ }^{83-85} \mathrm{IHH}$ is expressed at the prehypertrophic-hypertrophic boundary. Since PTHrP, ADAMTS-7, and ADAMTS-12 all function as negative regulators of chondrogenesis, these molecules have the potential to function within the same regulatory pathway. Data from real-time PCR, immunoflourescent cell staining, and immunoblotting assays all show that this is indeed the case: ADAMTS- 7 and -12 are highly induced downstream targets of PTHrP. ${ }^{78}$ These results have also been reproduced in vivo in PTHrP knockout mice, which exhibit reduced ADAMTS-7 and -12 expression. ${ }^{78}$ Further experimental data involving fetal mouse metatarsals has not only confirmed the role of ADAMTS-7 as a downstream mediator of PTHrP signaling, but has also confirmed that ADAMTS-7 is crucial for PTHrP-mediated inihibition of chondrocyte hypertrophy. ${ }^{78}$ The inhibition of chondrocyte hypertrophy, mineralization, and bone length by PTHrP is largely abolished by the addition of ADAMTS-7 antibody. Similar results have also been obtained in a micromass cell model with ADAMTS- $12 .{ }^{78}$ In addition, ADAMTS-12 can also enhance the expression of PTHrP, suggesting that ADAMTS-12 and PTHrP form a positive feedback regulatory loop in the course of chondrogenesis. ${ }^{82}$

As discussed above, GEP has been implicated in development, tissue regeneration, tumorigenesis, and inflammation. Our recent data demonstrates that GEP stimulates chondrocyte differentiation in mesenchymal stem cells in vitro and endochondral ossification ex vivo. GEP knockdown mice display dwarfism and striking skeletal defects. In addition, GEP activates chondrogenesis through Erk1/2 signaling, with JunB transcription factor being one of the key downstream molecules (Feng et al, unpublished data). 
Given that GEP enhances chondrocyte differentiation and bone growth, and that ADAMTS-7 associates with and converts GEP, ${ }^{78}$ it may be suggested that ADAMTS-7 inhibits chondrogensis by inhibiting the chondroinductive function of GEP. Indeed, both in vitro chondrogenic differentiation assays and ex vivo metatarsal culture experiments indicate this is the case (Figure 3). ${ }^{78,82}$

Interestingly, although ADAMTS-7 and ADAMTS-12 may negatively regulate chondrocyte differentiation, they can also exert a stimulatory effect on chondrocyte proliferation, a feature that they share with PTHrP. ${ }^{78,82}$ Given these two effects, it remains to be determined how ADAMTS-7 and ADAMTS-12 affect cartilage development and endochondral bone formation in vivo.

\section{Role in atherosclerosis}

Interestingly, ADAMTS-7 and its ability to interact with COMP, have also been implicated in the pathogenesis of vascular disease processes including atherosclerosis, restenosis after coronary angioplasty, and late failure of vein grafting. These processes all feature media-to-intima migration of vascular smooth muscle cells (VSMCs), which results in thickening of the vessel's intimal layer. ${ }^{86-88}$ This migratory process requires the protease-mediated degradation and remodeling of ECM, which forms a barrier to VSMC migration. ${ }^{89}$ MMPs such as MMP-2, MMP-9, and MT1-MMP have been implicated in this process. ${ }^{90,91} \mathrm{COMP}$, which is a component of vascular ECM and has been found in atherosclerotic lesions, is thought to be involved in the migration of VSMCs as well. ${ }^{92}$

The interplay between ADAMTS-7 and COMP has been examined in a recent study involving a model of ballooninjured rat carotid arteries. ADAMTS-7, which is localized in VSMCs, shows significantly increased levels in response to neointimal vessel injury. ${ }^{28}$ In addition, ADAMTS-7 in VSMCs is also induced by proinflammatory cytokines, such as TNF- $\alpha$ and IL- $1 \beta .{ }^{28}$ This result, similar to the one seen in chondrocytes, suggests that the role of ADAMTS-7 as a mediator of inflammation may be maintained across different tissue types. Of note, the anti-inflammatory signaling molecule TGF- $\beta$ has been found to downregulate ADAMTS-7. ${ }^{28}$ Additionally, ADAMTS-7 is induced by TNF-pathway transcription factors NF- $\kappa$ B and AP-1, further solidifying its role in this regulatory cascade. ${ }^{28}$

The supportive role of ADAMTS-7 in VSMC migration is established by data showing that VSMCs infected with ADAMTS-7 adenovirus exhibit significantly greater migration activity. ${ }^{28}$ This result is also seen in vivo, where

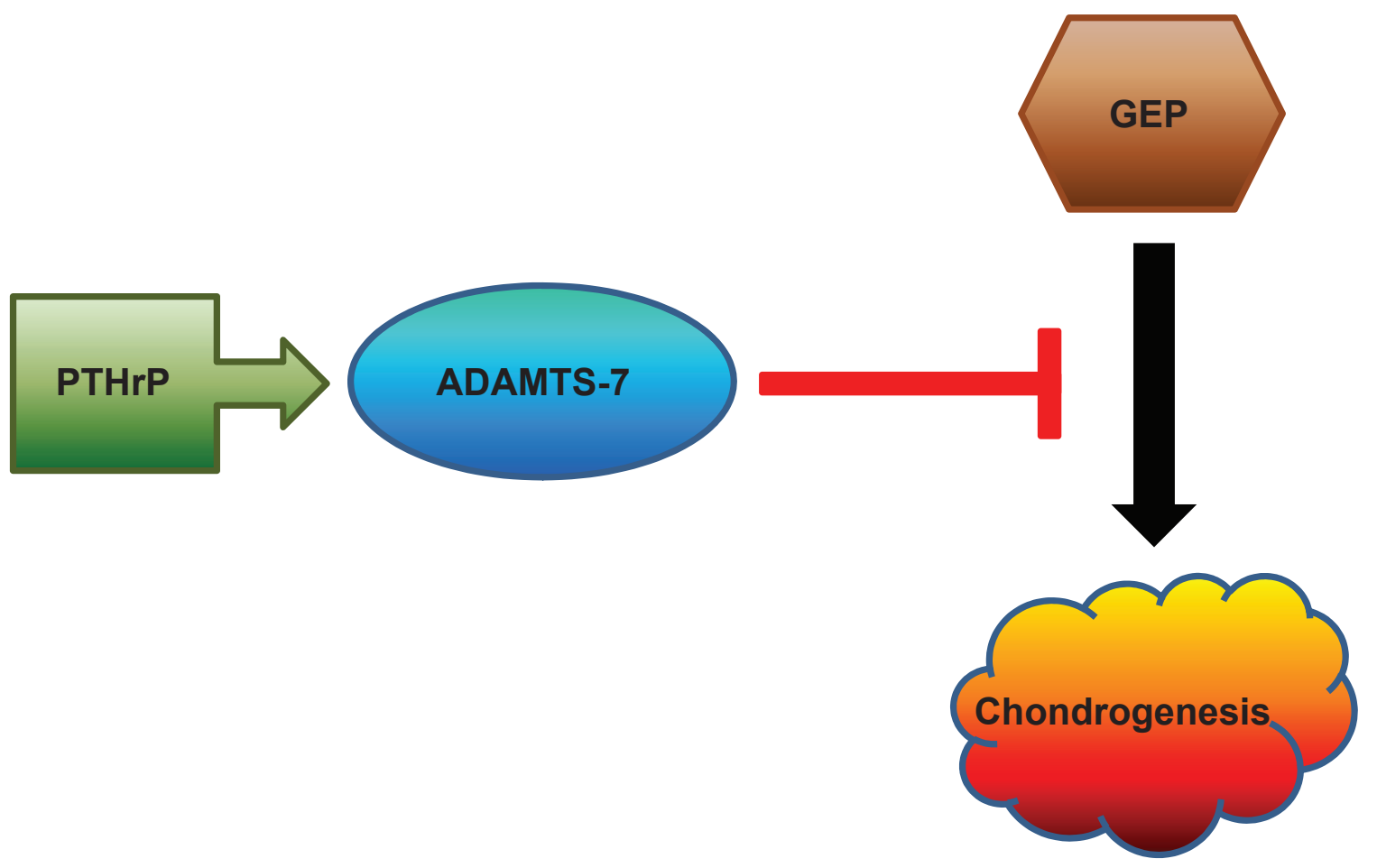

Figure 3 A proposed model for explaining ADAMTS-7-mediated inhibition of chondrogenesis. ADAMTS-7, a direct target of PTHrP, inhibits chondrogenesis by associating with GEP growth factor and inactivating its chondroinductive activity.

Abbreviations: ADAMTS, a disintegrin and metalloproteinase with thrombospondin motifs; GEP, granulin-epithelin precursor; PTHrP, . 
injured rat vessel walls exposed to ADAMTS-7 adenovirus show significantly greater neointima formation. Knockdown of ADAMTS-7 via perivascularly applied ADAMTS-7 siRNA results in significantly reduced neointima area, thus creating the potential that future therapeutic approaches could be developed using this strategy. ${ }^{28}$

Following vessel injury, levels of full-length COMP are decreased, while levels of COMP fragment are increased. ${ }^{28}$ Previous in vitro and in vivo assays have already established that ADAMTS-7 binds and cleaves COMP in chondrocytes and similar data has shown that this is also true in damaged vessels. VSMCs infected with ADAMTS-7 adenovirus display increased levels of COMP fragment. Furthermore, infection with COMP adenovirus resulted in decreased ADAMTS-7-mediated VSMC migration and neointima formation, both in vitro and in vivo. ${ }^{28}$ These data strongly suggest that the cleavage of COMP by ADAMTS-7 is a key event which is required for the migration of VSMCs and the pathogenesis of atherosclerotic disease.

\section{Role in cancer}

Many members of the ADAMTS family are dysregulated in a variety of tumors. For example, ADAMTS- 6 and -18 have been linked to breast cancer and expression of ADAMTS-8 and -15 are predictors of survival;,, 93 ADAMTS-19 may play a role in osteosarcoma; ${ }^{44}$ ADAMTS-20 is dysregulated in breast and colon cancer; ${ }^{95}$ and ADAMTS-4 and -5 are associated with glioblastoma. ${ }^{96,97}$ This is unsurprising since ADAMTSs belong to the family of MMPs, which are thought to play a key role in tumor growth, invasion, and metastasis..$^{98-103}$ Data concerning the potential role of ADAMTS-7 and - 12 in malignancy is just beginning to emerge. One study detected ADAMTS-7 in the urine of patients with prostate, brain, bladder, breast, and liver carcinomas. ${ }^{3}$ Further analysis has found that ADAMTS-7 is present in the urine of breast, bladder, and prostate carcinoma patients, but not in control urine, suggesting that ADAMTS-7 may play a role in growth and invasion of these tumors. ${ }^{3}$

Another study involving Madin-Darby canine kidney (MDCK) cells has found that overexpression of ADAMTS-12 confers protection from a tumorigenic phenotype that is generated in the presence of hematocyte growth factor. ${ }^{6}$ Further analysis has found that this effect is mediated by inhibition of the Ras-MAPK signaling pathway, and that such inhibition involves the thrombospondin domains of ADAMTS-12. ${ }^{6}$ The antitumor property of ADAMTS-12 can also be observed in vivo, as tumors induced by injecting immunodeficient SCID (severe combined immunodeficient) mice with A549 cells are markedly growth deficient when the injected cells are overexpressing ADAMTS-12, in comparison to control cells. ${ }^{6}$ Overall, the data suggest that ADAMTS-12 exerts a significant antitumor effect; a finding that may pave the way for the development of future therapy.

\section{Other roles}

Genetic analysis has also provided evidence that ADAMTS-7 and ADAMTS-12 may be involved in other diseases. Gene mapping data has found several single-nucleotide polymorphisms (SNPs) in the ADAMTS-7 gene which are linked to the gene for keratoconus with cataract, suggesting an association with this disease. ${ }^{104}$ However, none of these mutations are considered pathogenic, as they were also found in control samples.

Several variants of ADAMTS-12 are linked to bronchial hyper-responsiveness and asthma. In one study, the SNPs of ADAMTS-12 were found to be significantly different between cases and controls. ${ }^{105}$

\section{Summary and perspectives}

Although ADAMTS-7 and -12 are both known to play a role in the pathogenesis of arthritis, recent evidence has emerged to implicate these two molecules in a host of other biological and disease processes. Indeed, the potential roles of ADAMTS-7 and -12 in the pathogenesis of today's most common and costly diseases, including arthritis, atherosclerosis, and cancer, highlight the importance of future study (Table 2). Of particular note, elucidating the functional pathways involving these molecules in one disease may lead to open avenues of discovery in the understanding of other disorders. For example, the binding and cleavage of COMP, a feature that is crucial to the role of ADAMTS-7 and -12 in the progression of arthritis, may also help to explain the pathogenesis of atherosclerotic disease. Learning the full relationship between ADAMTS-7 and -12 and their binding partners, such as COMP and GEP, holds the promise of helping us to better understand the pathogenesis of, as well as

Table 2 Role of ADAMTS-7 and - 12 in biological and disease processes

\begin{tabular}{lll}
\hline Process & $\begin{array}{l}\text { Molecules/pathways } \\
\text { involved }\end{array}$ & References \\
\hline Arthritis & COMP, GEP & $27,41,54,65,66,68-70$ \\
Chondrogenesis & PTHrP, GEP & 68,69 \\
Atherosclerosis & COMP, TGF- $\beta$ & 26 \\
Cancer & ErkI/2 & 1,4 \\
\hline
\end{tabular}

Abbreviations: ADAMTS, a disintegrin and metalloproteinase with thrombospondin motifs; COMP, cartilage oligomeric matrix protein; GEP, granulin-epithelin precursor; PTHrP, ; TGF- $\beta$, transforming growth factor- $\beta$. 
develop effective therapies for some of today's most common and costly diseases.

\section{Acknowledgments}

C J Liu is grateful to his gifted collaborators who made the explorations in his laboratory possible. We apologize to the scientists who made contributions to the field, but have not been cited due to space limitations. Studies in the authors' laboratory were aided by National Institutes of Health research grants AR050620, AR053210, and AG029388 and a grant from the Arthritis National Research Foundation. The authors report no conflicts of interest in this work.

\section{References}

1. Kuno K, Matsushima K. ADAMTS-1 protein anchors at the extracellular matrix through the thrombospondin type I motifs and its spacing region. J Biol Chem. 1998;273(22):13912-13917.

2. Tang BL. ADAMTS: a novel family of extracellular matrix proteases. Int J Biochem Cell Biol. 2001;33(1):33-44.

3. Roy R, Louis G, Loughlin KR, et al. Tumor-specific urinary matrix metalloproteinase fingerprinting: identification of high molecular weight urinary matrix metalloproteinase species. Clin Cancer Res. 2008;14(20):6610-6617.

4. Porter S, Clark IM, Kevorkian L, Edwards DR. The ADAMTS metalloproteinases. Biochem J. 2005;386(Pt 1):15-27.

5. Levy GG, Nichols WC, Lian EC, et al. Mutations in a member of the ADAMTS gene family cause thrombotic thrombocytopenic purpura. Nature. 2001;413(6855):488-494

6. Llamazares M, Obaya AJ, Moncada-Pazos A, et al. The ADAMTS12 metalloproteinase exhibits anti-tumorigenic properties through modulation of the Ras-dependent ERK signalling pathway. J Cell Sci. 2007;120(Pt 20):3544-3552.

7. Hovinga JA, Studt JD, Alberio L, Lammle B. von Willebrand factorcleaving protease (ADAMTS-13) activity determination in the diagnosis of thrombotic microangiopathies: the Swiss experience. Semin Hematol. 2004;41(1):75-82.

8. Shenkman B. The role of ADAMT-13 in platelet adhesion in flow: methods for diagnosis of thrombotic thrombocytopenic purpura. Pathophysiol Haemost Thromb. 2006;35(1-2):98-102.

9. Moake JL. von Willebrand factor, ADAMTS-13, and thrombotic thrombocytopenic purpura. Semin Hematol. 2004;41(1):4-14.

10. Colige A, Sieron AL, Li SW, et al. Human Ehlers-Danlos syndrome type VII $\mathrm{C}$ and bovine dermatosparaxis are caused by mutations in the procollagen I N-proteinase gene. Am J Hum Genet. 1999;65(2): 308-317.

11. Colige A, Nuytinck L, Hausser I, et al. Novel types of mutation responsible for the dermatosparactic type of Ehlers-Danlos syndrome (Type VIIC) and common polymorphisms in the ADAMTS2 gene. J Invest Dermatol. 2004;123(4):656-663.

12. Shindo T, Kurihara H, Kuno K, et al. ADAMTS-1: a metalloproteinasedisintegrin essential for normal growth, fertility, and organ morphology and function. J Clin Invest. 2000;105(10):1345-1352.

13. Basile DP, Fredrich K, Chelladurai B, Leonard EC, Parrish AR. Renal ischemia reperfusion inhibits VEGF expression and induces ADAMTS-1, a novel VEGF inhibitor. Am J Physiol Renal Physiol. 2008;294(4):F928-F936.

14. Nakamura A, Sakai Y, Ohata C, Komurasaki T. Expression and significance of a disintegrin and metalloproteinase with thrombospondin motifs (ADAMTS)-1 in an animal model of renal interstitial fibrosis induced by unilateral ureteral obstruction. Exp Toxicol Pathol. 2007;59(1):1-7.
15. Jonsson-Rylander AC, Nilsson T, Fritsche-Danielson R, et al. Role of ADAMTS-1 in atherosclerosis: remodeling of carotid artery, immunohistochemistry, and proteolysis of versican. Arterioscler Thromb Vasc Biol. 2005;25(1):180-185.

16. Sabatine MS, Ploughman L, Simonsen KL, et al. Association between ADAMTS1 matrix metalloproteinase gene variation, coronary heart disease, and benefit of statin therapy. Arterioscler Thromb Vasc Biol. 2008;28(3):562-567.

17. Wagsater D, Bjork H, Zhu C, et al. ADAMTS-4 and - 8 are inflammatory regulated enzymes expressed in macrophage-rich areas of human atherosclerotic plaques. Atherosclerosis. 2008;196(2):514-522.

18. Moriguchi-Goto S, Yamashita A, Tamura N, et al. ADAMTS-13 attenuates thrombus formation on type I collagen surface and disrupted plaques under flow conditions. Atherosclerosis. 2009;203(2): 409-416.

19. Sandy JD, Verscharen C. Analysis of aggrecan in human knee cartilage and synovial fluid indicates that aggrecanase (ADAMTS) activity is responsible for the catabolic turnover and loss of whole aggrecan whereas other protease activity is required for $\mathrm{C}$-terminal processing in vivo. Biochem J. 2001;358(Pt 3):615-626.

20. Abbaszade I, Liu RQ, Yang F, et al. Cloning and characterization of ADAMTS11, an aggrecanase from the ADAMTS family. J Biol Chem. 1999;274(33):23443-23450.

21. Lohmander LS, Neame PJ, Sandy JD. The structure of aggrecan fragments in human synovial fluid. Evidence that aggrecanase mediates cartilage degradation in inflammatory joint disease, joint injury, and osteoarthritis. Arthritis Rheum. 1993;36(9):1214-1222.

22. Malfait AM, Liu RQ, Ijiri K, Komiya S, Tortorella MD. Inhibition of ADAM-TS4 and ADAM-TS5 prevents aggrecan degradation in osteoarthritic cartilage. J Biol Chem. 2002;277(25):22201-22208.

23. Collins-Racie LA, Flannery CR, Zeng W, et al. ADAMTS- 8 exhibits aggrecanase activity and is expressed in human articular cartilage. Matrix Biol. 2004;23(4):219-230.

24. Glasson SS, Askew R, Sheppard B, et al. Deletion of active ADAMTS5 prevents cartilage degradation in a murine model of osteoarthritis. Nature. 2005;434(7033):644-648.

25. Kuno K, Okada Y, Kawashima H, et al. ADAMTS-1 cleaves a cartilage proteoglycan, aggrecan. FEBS Lett. 2000;478(3):241-245.

26. Stanton H, Rogerson FM, East CJ, et al. ADAMTS5 is the major aggrecanase in mouse cartilage in vivo and in vitro. Nature. 2005; 434(7033):648-652.

27. Tortorella MD, Burn TC, Pratta MA, et al. Purification and cloning of aggrecanase-1: a member of the ADAMTS family of proteins. Science. 1999;284(5420):1664-1666.

28. Wang L, Zheng J, Bai X, et al. ADAMTS-7 mediates vascular smooth muscle cell migration and neointima formation in balloon-injured rat arteries. Circ Res. 2009;104(5):688-698.

29. Liu CJ. The role of ADAMTS-7 and ADAMTS-12 in the pathogenesis of arthritis. Nat Clin Pract Rheumatol. 2009;5(1):38-45.

30. Burrage PS, Mix KS, Brinckerhoff CE. Matrix metalloproteinases: role in arthritis. Front Biosci. 2006;11:529-543.

31. Clark IM, Parker AE. Metalloproteinases: their role in arthritis and potential as therapeutic targets. Expert Opin Ther Targets. 2003;7(1): 19-34.

32. Fosang AJ, Rogerson FM, East CJ, Stanton H. ADAMTS-5: the story so far. Eur Cell Mater. 2008;15:11-26.

33. Jones GC, Riley GP. ADAMTS proteinases: a multi-domain, multifunctional family with roles in extracellular matrix turnover and arthritis. Arthritis Res Ther. 2005;7(4):160-169.

34. Murphy G, Lee MH. What are the roles of metalloproteinases in cartilage and bone damage? Ann Rheum Dis. 2005;64(Suppl 4):iv44-iv47.

35. Murphy G, Nagase H. Reappraising metalloproteinases in rheumatoid arthritis and osteoarthritis: destruction or repair? Nat Clin Pract Rheumatol. 2008;4(3):128-135

36. Rowan AD, Litherland GJ, Hui W, Milner JM. Metalloproteases as potential therapeutic targets in arthritis treatment. Expert Opin Ther Targets. 2008;12(1):1-18. 
37. Liu CJ, Kong W, Ilalov K, et al. ADAMTS-7: a metalloproteinase that directly binds to and degrades cartilage oligomeric matrix protein. FASEB J. 2006;20(7):988-990.

38. Kevorkian L, Young DA, Darrah C, et al. Expression profiling of metalloproteinases and their inhibitors in cartilage. Arthritis Rheum. 2004;50(1):131-141.

39. Bevitt DJ, Mohamed J, Catterall JB, et al. Expression of ADAMTS metalloproteinases in the retinal pigment epithelium derived cell line ARPE-19: transcriptional regulation by TNFalpha. Biochim Biophys Acta. 2003;1626(1-3):83-91.

40. Cross AK, Haddock G, Stock CJ, et al. ADAMTS-1 and -4 are up-regulated following transient middle cerebral artery occlusion in the rat and their expression is modulated by TNF in cultured astrocytes. Brain Res. 2006;1088(1):19-30.

41. Voros G, Maquoi E, Collen D, Lijnen HR. Differential expression of plasminogen activator inhibitor-1, tumor necrosis factor-alpha, TNF-alpha converting enzyme and ADAMTS family members in murine fat territories. Biochim Biophys Acta. 2003;1625(1):36-42.

42. Tagoe CE, Marjanovic N, Park JY, et al. Annexin-1 mediates TNF-alpha-stimulated matrix metalloproteinase secretion from rheumatoid arthritis synovial fibroblasts. J Immunol. 2008;181(4):2813-2820.

43. Yun HJ, Yoo WH, Han MK, Lee YR, Kim JS, Lee SI. Epigallocatechin3-gallate suppresses TNF-alpha -induced production of MMP-1 and -3 in rheumatoid arthritis synovial fibroblasts. Rheumatol Int 2008;29(1):23-29.

44. Luan Y, Kong L, Howell DR, et al. Inhibition of ADAMTS-7 and ADAMTS-12 degradation of cartilage oligomeric matrix protein by alpha-2-macroglobulin. Osteoarthritis Cartilage. 2008;16(11): 1413-1420.

45. Cal S, Arguelles JM, Fernandez PL, Lopez-Otin C. Identification, characterization, and intracellular processing of ADAM-TS12, a novel human disintegrin with a complex structural organization involving multiple thrombospondin-1 repeats. J Biol Chem. 2001;276(21): 17932-17940.

46. Hedbom E, Antonsson P, Hjerpe A, et al. Cartilage matrix proteins. An acidic oligomeric protein (COMP) detected only in cartilage. J Biol Chem. 1992;267(9):6132-6136.

47. Briggs MD, Hoffman SM, King LM, et al. Pseudoachondroplasia and multiple epiphyseal dysplasia due to mutations in the cartilage oligomeric matrix protein gene. Nat Genet. 1995;10(3):330-336.

48. Briggs MD, Mortier GR, Cole WG, et al. Diverse mutations in the gene for cartilage oligomeric matrix protein in the pseudoachondroplasiamultiple epiphyseal dysplasia disease spectrum. Am J Hum Genet. 1998;62(2):311-319.

49. Cohn DH, Briggs MD, King LM, et al. Mutations in the cartilage oligomeric matrix protein (COMP) gene in pseudoachondroplasia and multiple epiphyseal dysplasia. Ann N Y Acad Sci. 1996;785:188-194.

50. Hecht JT, Nelson LD, Crowder E, et al. Mutations in exon 17B of cartilage oligomeric matrix protein (COMP) cause pseudoachondroplasia. Nat Genet. 1995;10(3):325-329.

51. DiCesare P, Hauser N, Lehman D, Pasumarti S, Paulsson M. Cartilage oligomeric matrix protein (COMP) is an abundant component of tendon. FEBS Lett. 1994;354(2):237-240.

52. Chen FH, Thomas AO, Hecht JT, Goldring MB, Lawler J. Cartilage oligomeric matrix protein/thrombospondin 5 supports chondrocyte attachment through interaction with integrins. J Biol Chem. 2005; 280(38):32655-32661.

53. Chan I, Liu L, Hamada T, Sethuraman G, McGrath JA. The molecular basis of lipoid proteinosis: mutations in extracellular matrix protein 1 . Exp Dermatol. 2007;16(11):881-890.

54. Di Cesare PE, Chen FS, Moergelin M, et al. Matrix-matrix interaction of cartilage oligomeric matrix protein and fibronectin. Matrix Biol. 2002;21(5):461-470.

55. Mansson B, Carey D, Alini M, et al. Cartilage and bone metabolism in rheumatoid arthritis. Differences between rapid and slow progression of disease identified by serum markers of cartilage metabolism. J Clin Invest. 1995;95:1071-1077.
56. Rosenberg K, Olsson H, Morgelin M, Heinegard D. Cartilage oligomeric matrix protein shows high affinity zinc-dependent interaction with triple helical collagen. J Biol Chem. 1998;273:20397-20403.

57. Neidhart M, Hauser N, Paulsson M, DiCesare PE, Michel BA, Hauselmann HJ. Small fragments of cartilage oligomeric matrix protein in synovial fluid and serum as markers for cartilage degradation. $\mathrm{Br} J$ Rheumatol. 1997;36(11):1151-1160.

58. Saxne T, Heinegard D. Cartilage oligomeric matrix protein: a novel marker of cartilage turnover detectable in synovial fluid and blood. Br J Rheumatol. 1992;31(9):583-591.

59. Mansson B, Carey D, Alini M, et al. Cartilage and bone metabolism in rheumatoid arthritis. Differences between rapid and slow progression of disease identified by serum markers of cartilage metabolism. J Clin Invest. 1995;95(3):1071-1077.

60. Kraus VB, Huebner JL, Fink C, et al. Urea as a passive transport marker for arthritis biomarker studies. Arthritis Rheum. 2002;46(2): 420-427.

61. Misumi K, Vilim V, Hatazoe T, et al. Serum level of cartilage oligomeric matrix protein (COMP) in equine osteoarthritis. Equine Vet $J$. 2002;34(6):602-608.

62. Neidhart M. Elevated serum prolactin or elevated prolactin/cortisol ratio are associated with autoimmune processes in systemic lupus erythematosus and other connective tissue diseases. $J$ Rheumatol. 1996;23(3):476-481.

63. Lohmander LS, Ionescu M, Jugessur H, Poole AR. Changes in joint cartilage aggrecan after knee injury and in osteoarthritis. Arthritis Rheum. 1999;42(3):534-544.

64. Petersson IF, Boegard T, Svensson B, Heinegard D, Saxne T. Changes in cartilage and bone metabolism identified by serum markers in early osteoarthritis of the knee joint. Br J Rheumatol. 1998;37(1):46-50.

65. Ganu V, Goldberg R, Peppard J, et al. Inhibition of interleukin1alpha-induced cartilage oligomeric matrix protein degradation in bovine articular cartilage by matrix metalloproteinase inhibitors: potential role for matrix metalloproteinases in the generation of cartilage oligomeric matrix protein fragments in arthritic synovial fluid. Arthritis Rheum. 1998;41(12):2143-2151.

66. Stracke JO, Fosang AJ, Last K, et al. Matrix metalloproteinases 19 and 20 cleave aggrecan and cartilage oligomeric matrix protein (COMP). FEBS Lett. 2000;478(1-2):52-56.

67. Dickinson SC, Vankemmelbeke MN, Buttle DJ, Rosenberg K, Heinegard D, Hollander AP. Cleavage of cartilage oligomeric matrix protein (thrombospondin-5) by matrix metalloproteinases and a disintegrin and metalloproteinase with thrombospondin motifs. Matrix Biol. 2003;22(3):267-278.

68. Liu CJ, Kong W, Xu K, et al. ADAMTS-12 associates with and degrades cartilage oligomeric matrix protein. J Biol Chem. 2006;281(23): $15800-15808$

69. Martel-Pelletier J, Welsch DJ, Pelletier JP. Metalloproteases and inhibitors in arthritic diseases. Best Pract Res Clin Rheumatol. 2001;15(5):805-829.

70. Xu K, Zhang Y, Ilalov K, et al. Cartilage oligomeric matrix protein associates with granulin-epithelin precursor (GEP) and potentiates GEP-stimulated chondrocyte proliferation. J Biol Chem. 2007;282(15): 11347-11355.

71. Anakwe OO, Gerton GL. Acrosome biogenesis begins during meiosis: evidence from the synthesis and distribution of an acrosomal glycoprotein, acrogranin, during guinea pig spermatogenesis. Biol Reprod. 1990;42(2):317-328.

72. Ong CH, Bateman A. Progranulin (granulin-epithelin precursor, PC-cell derived growth factor, acrogranin) in proliferation and tumorigenesis. Histol Histopathol. 2003;18(4):1275-1288.

73. Wright WE, Sassoon DA, Lin VK. Myogenin, a factor regulating myogenesis, has a domain homologous to MyoD. Cell. 1989;56(4): 607-617.

74. Zhou J, Gao G, Crabb JW, Serrero G. Purification of an autocrine growth factor homologous with mouse epithelin precursor from a highly tumorigenic cell line. J Biol Chem. 1993;268(15):10863-10869. 
75. Davidson B, Alejandro E, Florenes VA, et al. Granulin-epithelin precursor is a novel prognostic marker in epithelial ovarian carcinoma. Cancer. 2004;100(10):2139-2147.

76. Lu R, Serrero G. Inhibition of PC cell-derived growth factor (PCDGF, epithelin/granulin precursor) expression by antisense PCDGF cDNA transfection inhibits tumorigenicity of the human breast carcinoma cell line MDA-MB-468. Proc Natl Acad Sci U S A. 2000;97(8): 3993-3998.

77. Zanocco-Marani T, Bateman A, Romano G, Valentinis B, He ZH, Baserga R. Biological activities and signaling pathways of the granulin/ epithelin precursor. Cancer Res. 1999;59(20):5331-5340.

78. Bai XH, Wang DW, Kong L, et al. ADAMTS-7, a direct target of PTHrP, adversely regulates endochondral bone growth by associating with and inactivating GEP growth factor. Mol Cell Biol. 2009;29(15): 4201-4219.

79. Zhu J, Nathan C, Jin W, et al. Conversion of proepithelin to epithelins: roles of SLPI and elastase in host defense and wound repair. Cell. 2002;111(6):867-878.

80. Hong SJ, Kang KW. Purification of granulin-like polypeptide from the blood-sucking leech, Hirudo nipponia. Protein Expr Purif. 1999;16(2): 340-346.

81. DiCesare PE, Morgelin M, Mann K, Paulsson M. Cartilage oligomeric matrix protein and thrombospondin 1. Purification from articular cartilage, electron microscopic structure, and chondrocyte binding. Eur J Biochem. 1994;223(3):927-937.

82. Bai XH, Wang DW, Luan Y, Yu XP, Liu CJ. Regulation of chondrocyte differentiation by ADAMTS-12 metalloproteinase depends on its enzymatic activity. Cell Mol Life Sci. 2009;66(4):667-680.

83. Kronenberg HM. PTHrP and skeletal development. Ann N Y Acad Sci. 2006;1068:1-13.

84. Burdan F, Szumilo J, Korobowicz A, et al. Morphology and physiology of the epiphyseal growth plate. Folia Histochem Cytobiol. 2009;47(1): 5-16.

85. Kronenberg HM, Chung U. The parathyroid hormone-related protein and Indian hedgehog feedback loop in the growth plate. Novartis Found Symp. 2001;232:144-152; discussion 147-152.

86. Newby AC, Zaltsman AB. Molecular mechanisms in intimal hyperplasia. J Pathol. 2000;190(3):300-309.

87. Davies MG, Hagen PO. Pathobiology of intimal hyperplasia. Br J Surg. 1994;81(9):1254-1269.

88. Rudijanto A. The role of vascular smooth muscle cells on the pathogenesis of atherosclerosis. Acta Med Indones. 2007;39(2):86-93.

89. Hu J, Van den Steen PE, Sang QX, Opdenakker G. Matrix metalloproteinase inhibitors as therapy for inflammatory and vascular diseases. Nat Rev Drug Discov. 2007;6(6):480-498.

90. Sluijter JP, de Kleijn DP, Pasterkamp G. Vascular remodeling and protease inhibition - bench to bedside. Cardiovasc Res. 2006;69(3): 595-603.

91. Newby AC. Matrix metalloproteinases regulate migration, proliferation, and death of vascular smooth muscle cells by degrading matrix and non-matrix substrates. Cardiovasc Res. 2006;69(3):614-624.

92. Riessen R, Fenchel M, Chen H, Axel DI, Karsch KR, Lawler J. Cartilage oligomeric matrix protein (thrombospondin-5) is expressed by human vascular smooth muscle cells. Arterioscler Thromb Vasc Biol. 2001;21(1):47-54

93. Porter S, Span PN, Sweep FC, et al. ADAMTS8 and ADAMTS15 expression predicts survival in human breast carcinoma. Int J Cancer. 2006;118(5):1241-1247.

94. Cal S, Obaya AJ, Llamazares M, Garabaya C, Quesada V, Lopez-Otin C. Cloning, expression analysis, and structural characterization of seven novel human ADAMTSs, a family of metalloproteinases with disintegrin and thrombospondin-1 domains. Gene. 2002;283(1-2):49-62.

95. Llamazares M, Cal S, Quesada V, Lopez-Otin C. Identification and characterization of ADAMTS-20 defines a novel subfamily of metalloproteinases-disintegrins with multiple thrombospondin-1 repeats and a unique GON domain. J Biol Chem. 2003;278(15): $13382-13389$
96. Held-Feindt J, Paredes EB, Blomer U, et al. Matrix-degrading proteases ADAMTS4 and ADAMTS5 (disintegrins and metalloproteinases with thrombospondin motifs 4 and 5) are expressed in human glioblastomas. Int $J$ Cancer. 2006;118(1):55-61.

97. Nakada M, Miyamori H, Kita D, et al. Human glioblastomas overexpress ADAMTS-5 that degrades brevican. Acta Neuropathol. 2005;110(3):239-246

98. Deryugina EI, Quigley JP. Matrix metalloproteinases and tumor metastasis. Cancer Metastasis Rev. 2006;25(1):9-34.

99. Fingleton B. Matrix metalloproteinases: roles in cancer and metastasis. Front Biosci. 2006;11:479-491.

100. Jodele S, Blavier L, Yoon JM, DeClerck YA. Modifying the soil to affect the seed: role of stromal-derived matrix metalloproteinases in cancer progression. Cancer Metastasis Rev. 2006;25(1):35-43.

101. Noel A, Jost M, Maquoi E. Matrix metalloproteinases at cancer tumor-host interface. Semin Cell Dev Biol. 2008;19(1):52-60.

102. Orlichenko LS, Radisky DC. Matrix metalloproteinases stimulate epithelial-mesenchymal transition during tumor development. Clin Exp Metastasis. 2008;25(6):593-600.

103. Rydlova M, Holubec L Jr, Ludvikova M Jr, et al. Biological activity and clinical implications of the matrix metalloproteinases. Anticancer Res. 2008;28(2B):1389-1397.

104. Dash DP, Silvestri G, Hughes AE. Fine mapping of the keratoconus with cataract locus on chromosome $15 \mathrm{q}$ and candidate gene analysis. Mol Vis. 2006;12:499-505.

105. Kurz T, Hoffjan S, Hayes MG, et al. Fine mapping and positional candidate studies on chromosome 5 p13 identify multiple asthma susceptibility loci. J Allergy Clin Immunol. 2006;118(2):396-402.

106. Vazquez F, Hastings G, Ortega MA, et al. METH-1, a human ortholog of ADAMTS-1, and METH-2 are members of a new family of proteins with angio-inhibitory activity. J Biol Chem. 1999;274(33):23349-23357.

107. Mittaz L, Ricardo S, Martinez G, et al. Neonatal calyceal dilation and renal fibrosis resulting from loss of Adamts-1 in mouse kidney is due to a developmental dysgenesis. Nephrol Dial Transplant. 2005;20(2):419-423.

108. Lind T, McKie N, Wendel M, Racey SN, Birch MA. The hyalectan degrading ADAMTS-1 enzyme is expressed by osteoblasts and up-regulated at regions of new bone formation. Bone. 2005;36(3): 408-417.

109. Rehn AP, Birch MA, Karlstrom E, Wendel M, Lind T. ADAMTS-1 increases the three-dimensional growth of osteoblasts through type I collagen processing. Bone. 2007;41(2):231-238.

110. Brown HM, Dunning KR, Robker RL, Pritchard M, Russell DL. Requirement for ADAMTS-1 in extracellular matrix remodeling during ovarian folliculogenesis and lymphangiogenesis. Dev Biol. 2006;300(2):699-709

111. Shozu M, Minami N, Yokoyama H, et al. ADAMTS-1 is involved in normal follicular development, ovulatory process and organization of the medullary vascular network in the ovary. J Mol Endocrinol. 2005; 35(2):343-355.

112. Mittaz L, Russell DL, Wilson T, et al. Adamts- 1 is essential for the development and function of the urogenital system. Biol Reprod. 2004;70(4):1096-1105.

113. Rocks N, Paulissen G, Quesada-Calvo F, et al. ADAMTS-1 metalloproteinase promotes tumor development through the induction of a stromal reaction in vivo. Cancer Res. 2008;68(22):9541-9550.

114. Majumdar MK, Askew R, Schelling S, et al. Double-knockout of ADAMTS-4 and ADAMTS-5 in mice results in physiologically normal animals and prevents the progression of osteoarthritis. Arthritis Rheum. 2007;56(11):3670-3674.

115. Cheung KS, Hashimoto K, Yamada N, Roach HI. Expression of ADAMTS-4 by chondrocytes in the surface zone of human osteoarthritic cartilage is regulated by epigenetic DNA de-methylation. Rheumatol Int. 2009;29(5):525-534.

116. Song RH, Tortorella MD, Malfait AM, et al. Aggrecan degradation in human articular cartilage explants is mediated by both ADAMTS-4 and ADAMTS-5. Arthritis Rheum. 2007;56(2):575-585. 
117. Glasson SS, Askew R, Sheppard B, et al. Characterization of and osteoarthritis susceptibility in ADAMTS-4-knockout mice. Arthritis Rheum. 2004;50(8):2547-2558.

118. Corps AN, Jones GC, Harrall RL, Curry VA, Hazleman BL, Riley GP. The regulation of aggrecanase ADAMTS-4 expression in human Achilles tendon and tendon-derived cells. Matrix Biol. 2008; 27(5):393-401.

119. Tsuzaki M, Guyton G, Garrett W, et al. IL-1 beta induces COX2, MMP-1, -3 and -13, ADAMTS-4, IL-1 beta and IL-6 in human tendon cells. J Orthop Res. 2003;21(2):256-264.

120. Dunn JR, Reed JE, du Plessis DG, et al. Expression of ADAMTS-8, a secreted protease with antiangiogenic properties, is downregulated in brain tumours. Br J Cancer. 2006;94(8):1186-1193.
121. Demircan K, Hirohata S, Nishida K, et al. ADAMTS-9 is synergistically induced by interleukin-1beta and tumor necrosis factor alpha in OUMS-27 chondrosarcoma cells and in human chondrocytes. Arthritis Rheum. 2005;52(5):1451-1460.

122. Li Z, Nardi MA, Li YS, et al. C-terminal ADAMTS-18 fragment induces oxidative platelet fragmentation, dissolves platelet aggregates, and protects against carotid artery occlusion and cerebral stroke. Blood. 2009;113(24):6051-6060.

\section{Publish your work in this journal}

Open Access Rheumatology Research and Reviews is an international peer-reviewed, open access journal, publishing all aspects of clinical and experimental rheumatology in the clinic and laboratory including the following topics: Pathology, pathophysiology of rheumatologica diseases; Investigation, treatment and management of rheumatological

Submit your manuscript here: http://www.dovepress.com/open-access-rheumatology-research-and-reviews-journal diseases; Clinical trials and novel pharmacological approaches for the treatment of rheumatological disorders. The manuscript management system is completely online and includes a very quick and fair peerreview system, which is all easy to use. Visit http://www.dovepress.com/ testimonials.php to read real quotes from published authors. 